\title{
Comorbidities and cardiovascular risk factors in patients with psoriasis*
}

\author{
Isabela Guimarães Ribeiro Baeta ${ }^{1}$ \\ Bernardo Gontijo ${ }^{2}$
}

\author{
Flávia Vasques Bittencourt ${ }^{2}$ \\ Eugênio Marcos Andrade Goulart ${ }^{2}$
}

DOI: $h$ ttp://dx.doi.org/10.1590/abd1806-4841.20142874

\begin{abstract}
BACKGROUND: Psoriasis is a chronic inflammatory disease and its pathogenesis involves an interaction between genetic, environmental, and immunological factors. Recent studies have suggested that the chronic inflammatory nature of psoriasis may predispose to an association with other inflammatory diseases, especially cardiovascular diseases and metabolic disorders.

Objectives: To describe the demographic, clinical, epidemiological, and laboratory characteristics of a sample of psoriasis patients; to assess the prevalence of cardiovascular comorbidities in this group of patients; and to identify the cardiovascular risk profile using the Framingham risk score.

Methods: We conducted a cross-sectional study involving the assessment of 190 patients. Participants underwent history and physical examination. They also completed a specific questionnaire about epidemiological data, past medical history, and comorbidities. The cardiovascular risk profile was calculated using the Framingham risk score.

RESUlTS: Patients' mean age was $51.5 \pm 14$ years, and the predominant clinical presentation was plaque psoriasis $(78.4 \%)$. We found an increased prevalence of systemic hypertension, type 2 diabetes, metabolic syndrome, and obesity. Increased waist circumference was also found in addition to a considerable prevalence of depression, smoking, and regular alcohol intake. Patients' cardiovascular risk was high according to the Framingham risk score, and $47.2 \%$ of patients had moderate or high risk of fatal and non-fatal coronary events in 10 years.

CONCLUSIONS: Patients had high prevalence of cardiovascular comorbidities, and high cardiovascular risk according to the Framingham risk score. Further epidemiological studies are needed in Brazil for validation of our results.
\end{abstract}

Keywords: Comorbidity; Cardiovascular diseases; Psoriasis

\section{INTRODUCTION}

Psoriasis is a chronic and recurrent condition defined as an immunologically mediated inflammatory disease affecting mainly the skin and joints. The pathogenesis of psoriasis remains unclear, but it is known that genetic, environmental, and immunological factors are implicated. ${ }^{1}$

In recent years, the association of psoriasis with several comorbidities, such as obesity, metabolic syndrome (MS), systemic hypertension (SH), dyslipidemia, type 2 diabetes, malignancies, inflammatory bowel diseases, and habits, such as smoking and alcohol abuse has been matter of debate..$^{2,3}$ This association between psoriasis and comorbidities, especially cardiovascular and metabolic disorders, may be related to their chronic and inflammatory nature, especially due to increased pro-inflammatory cytokines that are part of the pathophysiology of such disorders., Recently the discussion has extended about higher prevalence of atherosclerosis, arterial calcification, and mortality related to cardiovascular events, such as acute myocardial infarction (AMI) and stroke. ${ }^{6,7}$ The chronic inflammatory process of psoriasis involves mechanisms that cause oxidative stress and free radical production, prompting the formation of atherosclerotic plaques on vessel walls and leading to an increased risk of cardiovascular disease. ${ }^{8}$

Results of epidemiological reports and studies investigating the association with comorbidities vary depending on the population studied. For this reason this study was designed with the purpose of defining

Received on 15.06.2013

Approved by the Advisory Board and accepted for publication on 15.11.2013.

* Study conducted at Outpatient Clinic of Dermatology, Hospital das Clínicas, Universidade Federal de Minas Gerais (UFMG) - Belo Horizonte (MG), Brazil.

Conflict of interest: None

Financial funding: None

Universidade Federal de São João Del-Rei (UFSJ) - São João Del Rei (MG), Brazil.

Universidade Federal de Minas Gerais (UFMG) - Belo Horizonte (MG), Brazil.

(C)2014 by Anais Brasileiros de Dermatologia 
the epidemiological, clinical, and laboratory profile of patients seen at a reference center for dermatology. Other objectives were to investigate the association with comorbidities and cardiovascular risk factors such as $\mathrm{SH}$, type 2 diabetes, obesity, dyslipidemia, and to define the profile of cardiovascular risk based on the Framingham risk score.

\section{PATIENTS AND METHODS}

We conducted an observational, cross-sectional study with convenience sampling. We assessed one hundred and ninety patients seen at the Department of Dermatology of the Hospital das Clínicas, Universidade Federal de Minas Gerais (HC/UFMG), Brazil, from July 2011 to May 2012. Patients older than 18 years who signed a written consent form were included in the study. This research project was approved by the Review Board of the institution. -

Patient's data such as age, sex, and skin color, time to diagnosis, and family history of psoriasis in first- and second-degree relatives were collected. Personal history of other comorbidities was investigated, particularly $\mathrm{SH}$, type 2 diabetes, dyslipidemia, depression, continued use medications, and family history of cardiovascular events (angina, AMI, stroke, revascularization surgery, angioplasty).

Patients completed the DLQI (Dermatology Life Quality Index), which was translated into and validated for Brazilian Portuguese. ${ }^{9}$

Smoking habits were investigated, and patients were divided into three categories: no smoking, previous smoking (smoking cessation more than a year before the date of the interview), and current smoking (calculating the number of pack-years).$^{10}$ Current smokers were asked whether they started smoking before they were diagnosed with psoriasis.

In terms of alcohol intake, patients were divided in those who do not consume alcohol regularly (less than once a month), those who currently consume alcohol regularly (more than once a month), and those who reported alcohol intake in the past. Patients reporting regular alcohol consumption were classified according to its frequency: low (less than once a week), moderate (one to three times a week), high (between four times a week and once a day), and very high (more than once a day). ${ }^{11}$

Skin lesions were graded according to their extension, erythema, infiltration, and desquamation using the Psoriasis Area Severity Index (PASI). ${ }^{12}$

Patients with PASI score $>10$ and/or with a DLQI score $>10$ based on Finlay's rule of tens were considered to have severe psoriasis. ${ }^{13}$ Patients currently on systemic medication were included in the group due to the severity of their condition, which is in agreement with the literature. ${ }^{14,15}$ This was based on the fact that many of the patients who were on systemic medication had a stable skin condition and did not meet the criteria of the rule of tens for being on systemic drugs.

Weight, height, waist circumference, and blood pressure were measured during physical examination. Body mass index (BMI) was calculated using the standard formula: BMI $=$ Weight $(\mathrm{kg}) /$ Height $(\mathrm{m})^{2}$.

Results of laboratory tests, such as total cholesterol (TC), high-density lipoprotein (HDL) cholesterol, low-density lipoprotein (LDL) cholesterol, triglycerides (TG), and fasting blood glucose, were collected from medical records. We considered the latest tests and did not include those carried out more than six months before the date of the interview.. Dyslipidemia was defined by previous diagnosis and treatment with lipid-lowering medications or if $\mathrm{TC} \geq 200 \mathrm{mg} / \mathrm{dl}$ and/or LDL-C $\geq 160 \mathrm{mg} / \mathrm{dl}$ and/or HDL-C $<50 \mathrm{mg} / \mathrm{dl}$ for women or $<40 \mathrm{mg} / \mathrm{dl}$ for men and/or TG $\geq 150$ $\mathrm{mg} / \mathrm{dl}^{16}$

The criteria of the National Cholesterol Education Program - Adult Treatment Panel (NCEPATP III) were used to define MS. ${ }^{17}$ The assessment of cardiovascular risk was based on the Framingham risk score, which takes into account sex, age, TC, HDL, systolic and diastolic blood pressure, diabetes, and smoking, and estimates the risk of fatal or nonfatal coronary events in 10 years. Patients were stratified into risk categories: low ( $<10 \%$ events in 10 years), moderate $(10-20 \%)$, and high $(>20 \%){ }^{18}$

In the statistical analysis, qualitative variables were expressed as absolute and percentage values. The quantitative variables were expressed as mean, standard deviation, median, and interquartile range. The chi-square test was used to compare proportions; Student's t-test was used to compare two means; and when the variables did not have a Gaussian distribution, the medians were compared using the KruskalWallis test. The threshold of statistical significance was set at $\mathrm{p}<0.05$. The EPI INFO 6.04 (CDC, Atlanta, USA) was used for the statistical analysis.

\section{RESULTS}

\section{General characteristics}

The sample's mean age was 51.5 years $( \pm 14)$, ranging from 18 to 92 years; 93 men $(48.9 \%)$ and 97 women $(51.1 \%)$ were evaluated. The mean diagnosis time was 15.8 years $( \pm 12.2)$, with median of 13 years (interquartile range between 6.0 and 23.0). Regarding skin color, 80 patients were caucasians $(42.1 \%), 81$ mulattos (42.6\%), and 29 African descendents (15.3\%).

Of the 190 patients, $149(78.4 \%)$ had a diagnosis of plaque psoriasis; 18 (9.5\%) had palmoplantar psoriasis; 11 (5.8\%) had guttate psoriasis; six (3.2\%) had generalized pustular psoriasis; five $(2.6 \%)$ had eryth- 
rodermic psoriasis; and only one $(0.5 \%)$ had a diagnosis of Hallopeau's continuous acrodermatitis.

Regarding therapeutic modality, 79 patients were only on an topical treatment $(41.6 \%) ; 59$ were on methotrexate $(31.1 \%)$; 27 were on acitretin $(14.2 \%)$; on phototherapy (10\%); 16 on immunobiological medications $(8.4 \%)$; and only one on cyclosporine $(0.5 \%)$. With regard to the family history of psoriasis, 57 patients $(30 \%)$ reported positive family history; 129 patients $(67.9 \%)$ denied a family history of psoriasis, and four $(2.1 \%)$ were not able to answer this item.

In relation to the severity of the skin condition, 128 patients $(67.4 \%)$ were considered to have severe psoriasis.

Of the 190 participants, $37(19.5 \%)$ had a previous diagnosis of psoriatic arthritis (PA). Of these, 17 (45.9\%) were classified as asymmetric oligoarthritis; $10(27 \%)$ as symmetric polyarthritis; six $(16.2 \%)$ as interphalangeal arthritis; and four $(10.8 \%)$ had spondylitis. No patient showed arthritis mutilans.

The mean PASI score was $3.4( \pm 3.03)$, with a median of 2.3 (interquartile range $=0.9$ to 4.5 ). Of the patients evaluated using the PASI, $17(10.5 \%)$ has a PASI score $\geq 10$. Regarding the DLQI, 26 patients (13.7\%) had a DLQI score $\geq 10$.

One hundred and eighteen patients $(62.1 \%)$ had nail involvement. The most frequent alteration was onycholysis (41.6\% of patients), followed by nail pitting $(21.6 \%)$, onychodystrophy $(14.2 \%)$, subungual hyperkeratosis $(11.6 \%)$, oil spot $(4.2 \%)$, and subungual hemorrhage $(11.1 \%)$.

Of the 190 patients, 39 (20.5\%) reported current smoking; $57(30 \%)$ reported past smoking; and 94 $(49.5 \%)$ reported they had never smoked. Most of the 96 patients reporting current or past smoking started smoking before the diagnosis of psoriasis $(76.5 \%)$. The mean time of current or past smoking was $22.3( \pm 12$ years), with a median of 20 years. The mean packyears was $21.3( \pm 16)$.

Considering alcohol consumption, 105 patients $(55.3 \%)$ reported they did not consume alcohol regularly, 31 (16.3\%) reported alcohol intake in the past, and 54 patients $(28.4 \%)$ reported current alcohol consumption. Of the 54 patients who regularly consumed alcohol, $36(66.6 \%)$ reported low consumption (less than once a week) and $18(33.4 \%)$ reported moderate consumption (one to three times a week). No patient reported high or very high consumption.

The patients' clinical characteristics are summarized in table 1 .

\section{Comorbidities and laboratory data}

Eighty-three patients (43.7\%) reported previous diagnosis of $\mathrm{SH}, 49(25.8 \%)$ had received a previous diagnosis of depression, and $29(15.3 \%)$ had been diagnosed with type 2 diabetes. Forty-eight patients $(25.3 \%)$ reported previous diagnosis of dyslipidemia. Regarding laboratory tests, $18.5 \%$ of patients had increased TC, $16.9 \%$ had increased LDL, and 33.7\% had increased TG. Sixty-six men (74.2\%) and 15 women $(16.9 \%)$ had low HDL. Sixty-eight patients $(64.3 \%)$ had high BMI. The overweight frequency was $31.1 \%$, and $33.2 \%$ of patients were considered obese (22.6\% with grade I obesity, $7.4 \%$ with grade II obesity, and $3.2 \%$ with grade III obesity).

In relation to waist circumference, $68.8 \%$ of men and $86.5 \%$ of women had increased measures $(p=0.005)$. Considering the cutoff point suggested by the WHO as a significant biomarker for cardiovascular risk, $38.7 \%$ of men and $78.4 \%$ of women had alterations $(\mathrm{p}<0.0001)$.

Eighty patients $(44.9 \%)$ met the criteria for the diagnosis of MS according to the NCEP-ATP III ( $42.6 \%$ of men and $47.2 \%$ of women).

The frequencies for the patients' comorbidities and laboratory alterations are summarized in table 2 .

\section{Framingham risk score}

The Framingham risk score was used to evaluate 159 patients. Of those, $38.4 \%$ had moderate risk and $8.8 \%$ had high risk for the development of coronary heart diseases in 10 years. The median score was 8.0 (interquartile range $=4.0$ to 13.0). Male patients had a median score of 10.0, while among female patients the median score was 7.0. The difference between men and women was statistically significant (KruskalWallis test $=8.6 ; \mathrm{p}=0.0033)$. The mean was $10.5 \pm 9.1$.

\section{Variable analysis regarding the severity of psoriasis \\ Of the 190 patients, 128 were considered as} having severe psoriasis. The statistically different variables in terms of severity of psoriasis were:

- Time to diagnosis: severe patients had a mean diagnosis time of $17.5( \pm 12.3)$ years compared with a mean of $12.6( \pm 11.2)$ years among nonsevere patients. $P$-value $=0.0021$.

- Psoriatic arthritis (PsA): 34 (26.5\%) patients with severe psoriasis had concurrent diagnosis of PsA compared with only three $(4.8 \%)$ nonsevere patients. Pvalue $=0.0008$.

- Nail involvement: 91 (71.1\%) severe patients had nail involvement, while only 27 (43.5\%) of the nonsevere group had alterations of this type. P-value $=$ 0.0004 .

- BMI: 89 (69.5\%) patients of the severe group had BMI $\geq 25$ (considering overweight + obesity) compared with 33 (53.2\%) of the nonsevere group. However, when we only analyzed obesity, there was no statistical significance. 
TABle 1: Frequency distribution of clinical variables of the psoriasis patients of the Dermatology Service of HC-UFMG

\begin{tabular}{|c|c|c|c|c|c|}
\hline Variables & $\mathbf{n}$ & $\%$ & Variables & $\mathbf{n}$ & $\%$ \\
\hline Gender & & & \multicolumn{3}{|l|}{ Classification of arthritis $(n=37)$} \\
\hline Females & 97 & 51.1 & Asymmetric oligoarthritis & 17 & 45.9 \\
\hline Males & 93 & 48.9 & Symmetrical polyarthritis & 10 & 27.0 \\
\hline Skin color & & & Distal interphalangeal joint & 6 & 16.2 \\
\hline White & 80 & 42.1 & Spondylitis & 4 & 10.8 \\
\hline Brown & 81 & 42.6 & Mutilating arthritis & 0 & 0 \\
\hline Black & 29 & 15.3 & \multicolumn{3}{|l|}{ Nail involvement } \\
\hline Asian & 0 & 0 & Yes & 118 & 62.1 \\
\hline Clinical form & & & No & 72 & 37.9 \\
\hline Plaque psoriasis & 149 & 78.4 & \multicolumn{3}{|l|}{ Type of nail change $(n=118)$} \\
\hline Palmoplantar psoriasis & 18 & 9.5 & Onycholysis & 79 & $41.6^{*}$ \\
\hline Guttate psoriasis & 11 & 5.8 & Nail pitting & 41 & $21.6^{*}$ \\
\hline Generalized pustular psoriasis & 6 & 3.2 & Onychodystrophy & 27 & $14.2^{*}$ \\
\hline Erythrodermic psoriasis & 5 & 2.6 & Subungual hyperkeratosis & 22 & $11.6^{*}$ \\
\hline Continuous acrodermatitis & 1 & 0.5 & Oil spot & 8 & $4.2^{*}$ \\
\hline Treatment & & & Subungual hemorrhage & 21 & 11.1 \\
\hline Acitretin & 27 & $14.2^{*}$ & \multicolumn{3}{|c|}{ Psoriasis Area and Severity Index- PASI $(n=162)$} \\
\hline Cyclosporin & 1 & $0.5^{\star}$ & $\geq 10$ & 17 & 10.5 \\
\hline Phototherapy & 19 & $10.0^{*}$ & $<10$ & 145 & 89.5 \\
\hline Immunobiological & 16 & $8.4^{*}$ & \multicolumn{3}{|c|}{ Dermatology Life Quality Index - DLQI $(n=190)$} \\
\hline Methotrexate & 59 & $31.1^{*}$ & $\geq 10$ & 26 & 13.7 \\
\hline Exclusively topic & 79 & $41.6^{*}$ & $<10$ & 164 & 86.3 \\
\hline Biopsy & & & \multicolumn{3}{|l|}{ Smoking } \\
\hline Yes & 71 & 37.4 & Current & 39 & 20.5 \\
\hline No & 119 & 62.6 & Past & 57 & 30.0 \\
\hline Family history of psoriasis & & & Never smoked & 94 & 49.5 \\
\hline Yes & 57 & 30.0 & \multicolumn{3}{|l|}{ Alcoholism } \\
\hline No & 129 & 67.9 & Yes & 54 & 28.4 \\
\hline No data & 4 & 2.1 & Past & 31 & 16.3 \\
\hline Severity & & & No & 105 & 55.3 \\
\hline Yes & 128 & 67.4 & & & \\
\hline No & 62 & 32.6 & & & \\
\hline \multicolumn{6}{|l|}{ Arthritis } \\
\hline Yes & 37 & 19.5 & & & \\
\hline No & 153 & 80.5 & & & \\
\hline
\end{tabular}

The statistical analyses performed are described in table 3 .

Variable analysis regarding the classification of psoriasis

In terms of psoriasis classification, patients were divided into two groups: plaque psoriasis, and other clinical forms, with analysis of the clinical and laboratory variables between the two groups. Only PsA showed statistical significance: of the 37 patients with a diagnosis of PsA, 35 had plaque psoriasis and only two had other clinical forms of psoriasis $(23.5 \%$ vs. $4.9 \%$, p-value $=0.0146$ ).

\section{riatic arthritis \\ Relationship between nail changes and pso-}

The association between PsA and nail changes was analyzed, showing statistically significant results. Of the 37 patients with a diagnosis of PsA, 34 (91.2\%) had nail involvement $(\mathrm{p}$-value $=0.0001)$.
Prevalence of morbidities in the Brazilian population compared with our sample

Based on data from 2011 provided by the Instituto Brasileiro de Geografia e Estatística (IBGE), the prevalence of some morbidities in the Brazilian population was compared with our sample. A greatly increased prevalence of $\mathrm{SH}$, type 2 diabetes, smoking, overweight, and obesity was found in the 190 psoriasis patients compared with the general population. The prevalence of type 2 diabetes is worth noting, being 3 times higher in patients with psoriasis (Table 4). A comparison between the prevalence of MS in our sample and the existing data on the Brazilian population was also carried out from a population-based study conducted in Vitória. ${ }^{19}$ The difference between the groups was statistically significant, with $\mathrm{p}=$ 0.0310 . The analysis by sex did not show any statistical difference. 
TABLE 2: Frequency distribution of comorbidities and laboratory alterations of psoriasis patients of the Dermatology Service of HC-UFMG

\begin{tabular}{|c|c|c|c|c|c|}
\hline Variables & $\mathbf{n}$ & $\%$ & Variables & $\mathbf{n}$ & $\%$ \\
\hline Depression & & & Total cholesterol (mg/dl) $(\mathrm{n}=178)$ & & \\
\hline Yes & 49 & 25.8 & $<240$ & 145 & 81.5 \\
\hline No & 141 & 74.2 & $\geq 240$ & 33 & 18.5 \\
\hline Type 2 diabetes & & & LDL (mg/dl) $(\mathrm{n}=178)$ & & \\
\hline Yes & 29 & 15.3 & $<160$ & 148 & 83.1 \\
\hline No & 161 & 84.7 & $\geq 160$ & 30 & 16.9 \\
\hline Systemic hypertension & & & HDL (mg/dl) $(\mathrm{n}=178)$ & & \\
\hline Yes & 83 & 43.7 & Man & & \\
\hline No & 107 & 56.3 & $<50$ & 66 & 74.2 \\
\hline Dyslipidemia & & & $\geq 50$ & 23 & 25.8 \\
\hline Yes & 48 & 25.3 & Woman & & \\
\hline No & 142 & 74.7 & $<40$ & 15 & 16.9 \\
\hline Metabolic syndrome $(n=178)$ & & & $\geq 40$ & 74 & 83.1 \\
\hline Yes & 80 & 44.9 & Triglycerides $(\mathrm{mg} / \mathrm{dl})(\mathrm{n}=178)$ & & \\
\hline No & 98 & 55.1 & $<150$ & 118 & 66.3 \\
\hline $\operatorname{BMI}(n=190)$ & & & $\geq 150$ & 60 & 33.7 \\
\hline$<25$ & 68 & 35.7 & & & \\
\hline 25.0 to 29.9 & 59 & 31.1 & & & \\
\hline 30.0 to 34.9 & 43 & 22.6 & & & \\
\hline 35.0 to 39.9 & 14 & 7.4 & & & \\
\hline$\geq 40.0$ & 6 & 3.2 & & & \\
\hline \multicolumn{6}{|l|}{ Waist circumference $(\mathrm{cm})$} \\
\hline \multicolumn{6}{|l|}{ Man } \\
\hline$<94$ & 29 & 31.2 & & & \\
\hline$\geq 94$ to $<102$ & 28 & 30.1 & & & \\
\hline$\geq 102$ & 36 & 38.7 & & & \\
\hline \multicolumn{6}{|l|}{ Woman } \\
\hline$<80$ & 13 & 13.2 & & & \\
\hline$\geq 80$ to 88 & 8 & 8.2 & & & \\
\hline$\geq 88$ & 76 & 78.4 & & & \\
\hline
\end{tabular}

TABLE 3: Frequency distribution of clinical variables in relation to the severity of psoriasis in 190 patients of the Dermatology Service of HC-UFMG - statistically significant variables

\begin{tabular}{|c|c|c|c|c|}
\hline Variables & Severe & Mild & Statistical test & $\mathrm{p}$ value \\
\hline \multicolumn{5}{|l|}{ Arthritis } \\
\hline Yes & $34(26.5 \%)$ & $3(4.8 \%)$ & *11.22 & 0.0008 \\
\hline No & $94(73.5 \%)$ & $59(95.2 \%)$ & & \\
\hline \multicolumn{5}{|l|}{ Nail change } \\
\hline Yes & $91(71.1 \%)$ & $27(43.5 \%)$ & *12.32 & 0.0004 \\
\hline No & $37(28.9 \%)$ & $35(56.5 \%)$ & & \\
\hline \multicolumn{5}{|l|}{ Body mass index (BMI) } \\
\hline$<25$ & $39(30.5 \%)$ & $29(46.8 \%)$ & *4.15 & 0.042 \\
\hline$\geq 25$ (overweight + obesity) & $89(69.5 \%)$ & $33(53.2 \%)$ & & \\
\hline Time of diagnosis in years (median) & $15.0(8.0$ to 25.0$) \dagger$ & $8.0(4.0$ to 20.0$) \dagger$ & $* * 9.43$ & 0.0021 \\
\hline
\end{tabular}

${ }^{*}$ Chi-square test $\quad{ }^{* *}$ Kruskal-Wallis test $\quad \dagger$ Interquartile range

TABlE 4: Comparison of the prevalence of comorbidities between patients with psoriasis and the Brazilian population (Source: Vigitel 2011)

\begin{tabular}{lll}
\hline Morbidities & $\begin{array}{l}\text { Brazilian population } \\
\%(95 \% \mathrm{CI})\end{array}$ & $\begin{array}{l}\text { Patients with psoriasis } \\
\text { Total } \%(95 \% \mathrm{CI})\end{array}$ \\
\hline Systemic hypertension & $22.7(21.9$ to 23.5$)$ & $43.7(36.6$ to 51.0$)$ \\
Diabetes & $5.6(21.9$ to 6.0$)$ & $15.3(10.6$ to 21.3$)$ \\
Smoking & $14.8(13.9$ to 15.7$)$ & $20.5(15.2$ to 27.1$)$ \\
Overweight & $48.5(47.4$ to 49.7$)$ & $64.7(57.4$ to 71.4$)$ \\
Obesity & $15.8(15.0$ to 16.6$)$ & $33.2(26.6$ to 40.4$)$ \\
\hline
\end{tabular}

$95 \% \mathrm{CI}=95 \%$ confidence interval. 


\section{DISCUSSION}

The association between psoriasis and cardiovascular comorbidities has been widely described in recent years by epidemiological studies in different populations. However, the actual prevalence of associations in the Brazilian population still lacks specific data because even data on the epidemiology of psoriasis are scarce in Brazil.

The mean age of our patients was $51.5( \pm 14)$ years. This contributed to the findings of comorbidities such as $\mathrm{SH}$, type 2 diabetes, and dyslipidemia, whose prevalence rates increase with age. The mean time to diagnosis was also high, 15.8 years. Regarding skin color, it is known that psoriasis is more prevalent in Caucasians, with a low prevalence in AfricanAmericans. ${ }^{1}$ Due to the high level of miscegenation of the Brazilian population, assessment of ethnicity and/or skin color is extremely difficult and controversial. The was a prevalence of patients with white and brow skin $(42.1 \%$ and $42.6 \%$, respectively) in our sample, with lower prevalence of black skin (15.3\%). In agreement with the literature, there was no significant difference between sexes, since our sample consisted of $48.9 \%$ of men and $51.1 \%$ women.

The predominant clinical form was plaque psoriasis, accounting for most cases $(78.4 \%)$, followed by less frequent variables, as reported in epidemiological studies in other populations. ${ }^{1}$ The number of individuals with generalized pustular psoriasis and erythrodermic psoriasis, which are extremely rare variants, is worth noting because these clinical forms accounted for $5.8 \%$ of patients. Maybe because our study was conducted at a center of excellence for dermatology, it is likely to have many patients with more severe conditions.

Also in terms of psoriasis classification, we compared plaque psoriasis with other clinical forms with regard to clinical and laboratory characteristics of patients and comorbidities. The only variable that showed statistical significance was PsA, which was much more frequent in patients with psoriasis vulgaris. Of the 37 patients with PsA, 35 had plaque psoriasis, one patient had guttate psoriasis, and one patient had erythrodermic psoriasis). Psoriasis vulgaris is the main form of psoriasis associated with PsA, but pustular psoriasis and guttate psoriasis have also been correlated with PsA.

Nail involvement is a symptom of psoriasis, affecting up to $80 \%$ of patients during their lifetime. We found nail involvement in $62.1 \%$ of our sample. In disagreement with the literature, onycholysis was the most frequent alteration, found in $67 \%$ of our patients with nail changes. Nail pitting, which, according to epidemiological studies, represents the most common type of nail lesions in psoriasis patients, ${ }^{1}$ was found in 41 individuals in our sample $(21.5 \%$ of the total or
$34.7 \%$ of patients with nail changes). The large number of patients on systemic treatment in the present study might have influenced the frequency of nail changes. For example, acitretin may cause nail fragility with onychorexis, onychoschizia, and onycholysis; and phototherapy with oral psoralen may cause photo-onycholysis. Other drugs, such as methotrexate and immunobiological medication, may normalize keratinization and differentiation of epidermal cells, contributing to the reduction of changes in the nail matrix, such as nail pitting.

As for joint involvement, $19.5 \%$ of patients had a previous diagnosis of PsA, which is consistent with the prevalence reported in the literature. ${ }^{20}$ Many patients had joint complaints without even having a diagnosis of PsA. And this may be an underdiagnosed entity because of the difficulty in reaching a consensus on PsA diagnostic criteria. In addition to the diagnostic criteria, PsA classification according to the standards of joint involvement is also controversial. Moll and Wright classified PsA into five subtypes: asymmetric oligoarthritis, symmetric polyarthritis similar to rheumatoid arthritis, arthritis with a predominance of distal interphalangeal joints,arthritis mutilans, and spondylitic arthritis. ${ }^{21}$ In our study, asymmetric oligoarthritis was the most prevalent form, accounting for $45.9 \%$ of patients with PsA. The second most common form was symmetrical polyarthritis $(27 \%)$, followed by distal interphalangeal arthritis and spondylitic arthritis $(16.2 \%$ and $10.8 \%$, respectively). Arthritis mutilans is extremely rare and was not found in our patients. Many studies confirm our findings that oligoarthritis is the most prevalent form, including studies by Moll and Wright and a Brazilian study conducted by Bonfiglioli et al..$^{21,22}$ Other studies have shown polyarticular arthritis as the most frequent form, but there may be overlapped clinical forms, which makes it difficult to classify these specific categories. Some authors claim that oligoarthritis is more frequent in the early stages of psoriasis, with the possibility of developing into more extensive and severe forms. ${ }^{23}$

The association between PsA and nail involvement is well documented in the literature, and the severity of nail involvement may correlate with the severity of skin and joint conditions. Nail changes may be found in up to $90 \%$ of patients with a established diagnosis of PsA, especially when there is involvement ofdistal interphalangeal joints. ${ }^{24}$ Our data corroborate this percentage since $92 \%$ of our patients with arthritis had nail changes with proven statistical significance.

Regarding therapeutic modalities, it is worth noting the large number of patients on systemic treatment in our study: only $41.5 \%$ were using only topical medications. About $10 \%$ of our patients were on pho- 
totherapy, combined or not with other treatments, and $54.1 \%$ were using systemic medication. It is also noteworthy that there was a large number of patients using immunobiological medication (8.5\%), precisely because the study was conducted at a center of excellence, where there were more severe cases. The most commonly used systemic medication was methotrexate $(31 \%)$, followed by acitretin $(14 \%)$, and only one case of cyclosporine use.

Among the cardiovascular comorbidities, obesity is more intrinsically related to psoriasis. Behavioral changes and changes in the quality of life of psoriatic patients could contribute to weight gain. Similarly, obesity could predispose to the onset of skin diseases due to common inflammatory mechanisms. ${ }^{2}$ In our study, $64.3 \%$ of patients had high BMI: the frequency of overweight was $31.1 \%$, and $33.2 \%$ of patients were obese. Of the obese patients, $22.6 \%$ had grade I obesity; $7.4 \%$ had grade II obesity; and 3.2\% had grade III obesity. Because this was a cross-sectional study, it is not possible to state whether skin diseases predisposed to obesity, or vice versa. Unlike the study by Neimann et al., the presence of obesity was not related to the severity of psoriasis. ${ }^{15}$

Visceral obesity, represented by waist circumference, is known to be correlated with high metabolic and cardiovascular risk. The cutoff point commonly established for waist circumference, $102 \mathrm{~cm}$ for men and $88 \mathrm{~cm}$ for women, has been questioned because it is not appropriate for people of different ethnicities. In some studies, lower levels $-94 \mathrm{~cm}$ for men and $80 \mathrm{~cm}$ for women - have been considered more appropriate for our population. ${ }^{25}$ Considering these values, $68.8 \%$ of men and $86.5 \%$ of women had increased measures in our study. Considering the cutoff point of $102 \mathrm{~cm}$ for men and $88 \mathrm{~cm}$ for women, which suggests an even higher cardiovascular risk, $38.7 \%$ of men and $78.4 \%$ of women had increased measures. We noticed that, unlike men, most women remained in the highrisk group even when the cutoff point was increased.

The relationship between psoriasis and $\mathrm{SH}$ has also been well documented. Of our 190 patients, 43.7\% had a previous diagnosis of $\mathrm{SH}$. Comparing with the data of the Brazilian population, this is a significant difference, almost twice higher, according to the Ministry of Health $(43.7 \%$ vs. $22.7 \%){ }^{26}$ The difference between sexes was also significant $(19.5 \%$ vs. $39.8 \%$ in males and $27.4 \%$ vs. $47.4 \%$ in females). Five patients who denied having a previous diagnosis of $\mathrm{SH}$ or use of antihypertensive medication showed increased blood pressure levels during physical examination. These patients were referred for specialist follow-up. Unlike the study by Kimball et al., we found no difference in the prevalence of $\mathrm{SH}$ in relation to the psoriasis severity. ${ }^{27}$
In addition to $\mathrm{SH}$, type 2 diabetes is another important independent risk factor for cardiovascular disease that is associated with psoriasis, probably due to their common pro-inflammatory state. In our study, $15.3 \%$ of patients had a previous diagnosis of type 2 diabetes. There was a significant difference when we compared these data with the Brazilian population, whose prevalence is around $5.3 \%$, i.e., almost onethird of the value we found. ${ }^{26}$ Eight patients who did not have a diagnosis of type 2 diabetes showed increased glucose levels, but, similarly to $\mathrm{SH}$, the diagnosis of type 2 diabetes requires at least two increased measures. In relation to these patients, we requested additional laboratory tests and referred them to clinical follow-up. Diabetes is the comorbidity with the largest number of studies reporting its increased prevalence in proportion to the severity of psoriasis..$^{15,27,28}$ However, this difference was not found in our study.

Several studies have confirmed the association between psoriasis and altered lipid metabolism, such as reduced HDL and increased TG. ${ }^{211}$ In our study, 48 patients $(25.3 \%)$ reported a previous diagnosis of dyslipidemia. Regarding laboratory tests, it is worth noting the high rate of men with low HDL compared with women $(74.2 \%$ vs. $16.9 \%)$. Among patients who were taking acitretin, only five showed abnormal lipid profile, which probably did not affect the final data analysis.

MS is a set of cardiovascular risk factors, including $\mathrm{SH}$, abdominal obesity, dyslipidemia, and glucose intolerance. Despite the fact that SM has recently been questioned whether or not it represents an additional risk, we cannot fail to consider that it is a condition that aggregates multiple comorbidities that individually increase the patient's cardiovascular risk. Recent studies have shown a higher prevalence of MS in psoriasis patients, especially after the age of 40 , based on the pro-inflammatory nature of the two diseases. ${ }^{11,29}$ In the present study, $44.9 \%$ of patients met the criteria for diagnosis of MS according to the NCEP-ATP III. When compared to estimated prevalence for the Brazilian population, which is $29.8 \%,{ }^{19}$ there is a significant difference, which has been statistically proven $(p<0.0001)$. There was no correlation of MS with psoriasis severity, in disagreement with the findings by Langan et al., where the prevalence of metabolic alterations was directly proportional to the severity and extent of skin psoriasis. ${ }^{30}$

The association between smoking and psoriasis has been widely reported, both based on changes in the patient's quality of life and on the theory that smoking generates oxidative and inflammatory mechanisms that could predispose to the development of psoriasis. ${ }^{31}$ In our study, $50.5 \%$ of patients reported past or current smoking, which is the majority of our sample $(20.5 \%$ reported current smoking and 30\% 
reported they smoked in the past). Among the 96 patients who reported current or past smoking, the vast majority $(76.5 \%)$ reported that the onset of smoking occurred even before the diagnosis of psoriasis, i.e., maybe the oxidative stress caused by nicotine plays a role in the pathogenesis of psoriasis. Considering the time of smoking for smokers and exsmokers, the mean time was also high, $22.3 \pm 12$ years. Comparing the data from our study with data from the Ministry of Health, the prevalence of smoking was higher $(20.5 \%$ in our sample vs. $14.8 \%$ in the general population) ${ }^{26}$ Trying to quantify smoking, we calculated the number the "pack-years", that is, number of cigarettes smoked per day $\times$ number of years smoked ( 1 pack has 20 cigarettes). In our sample, mean packyears was $21.3 \pm 16$, at least twice the value of 10 packyears (considered high tobacco intake by the Brazilian Society of Pulmonology), which demonstrates a high consumption of our patients. ${ }^{32}$ Despite the high number of smokers, we found no relationship between smoking and psoriasis severity.

Similarly to smoking, the habit of drinking alcohol may start or even become more frequent after the development of psoriasis due mainly to changes related to quality of life. ${ }^{3}$ Some authors have also claimed that alcohol and its metabolites can stimulate keratinocyte proliferation and the production of inflammatory cytokines, which may contribute to the development of psoriasis. ${ }^{33}$ The quantification of alcohol consumption is extremely difficult and controversial, as there are different types of alcoholic beverages with varying alcohol content. In addition, the same amount of alcohol can have different effects on different individuals, depending on factors such as sex, age, and comorbidities.Several studies have reported the association of alcohol intake with psoriasis. Poikolainen et al. found a two-fold higher intake of alcohol in psoriasis patients compared with controls up to 12 months before the onset of psoriasis. ${ }^{34}$ In a prospective study, Qureshi et al. found 1.72 times the risk of developing psoriasis in alcoholic patients. ${ }^{35}$ Sommer et al. also described the association between alcohol abuse and psoriasis, in proportion to the amount of alcohol intake, in a significant magnitude, with OR ranging from 2.78 to $3.61 .^{11}$ Among our patients, only $28.4 \%$ reported current habit of alcohol intake, and of these, no patient had a diagnosis of alcoholism according to the CAGE questionnaire (Cutdown, Annoyed by criticism, Guilty and Eye-opener).

Psoriasis, as well as other skin diseases, can affect the patient's self-esteem, interfering with all aspects of quality of life. This results in an increase in the prevalence of mood disorders, especially anxiety and depression, often unrelated to the extent of skin involvement. The prevalence of depression in psoria- sis patients is about $20 \%$, and it is believed that depression onset can increase the risk for cardiovascular disease. ${ }^{36}$ In our study, the prevalence of depression was $25.8 \%$, but it was not related to the severity or extent of the skin condition.

Regarding major cardiovascular events, three patients reported past AMI, requiring angioplasty and one patient had a history of ischemic stroke. All four patients had a diagnosis of psoriasis when such events occurred.

According to the severity criteria used, $67.4 \%$ of patients were classified as having severe psoriasis. Some variables had statistical significance in relation to disease severity, such as time to diagnosis: severe patients had a mean time to diagnosis of $17.5( \pm 12.3)$ years compared to 12.6 ( \pm 11.2 years) in nonsevere patients. This may be due to the fact that severe patients are followed up by the health care facility, and patients with milder and/or controlled skin conditions are lost for follow-up precisely because they improved. Skin biopsy was also more frequently performed in severe patients, probably due to the need of accurate diagnostic confirmation before the start of a more aggressive therapy. The presence of PsA and nail involvement was also higher in critically ill patients, with high statistical significance $(p=0.0008$ and $p=$ 0.0004 , respectively). These data are consistent with the literature. ${ }^{21}$ Another finding that was statistically significant regarding severity was overweight.

Considering patients with BMI $\geq 25$ (overweight + obesity), they had a tendency to have more severe psoriasis. However, when obesity was separately analyzed, there was no statistical significance. Neimann et al. found a correlation between obesity and severity of psoriasis in a population-based study in the UK, even after adjustment for age and sex, and performing multivariate analysis. ${ }^{15}$

Cardiovascular diseases are a major cause of morbidity and mortality in Brazil and worldwide. Therefore, it is essential to identify individuals at higher risk for developing heart disease and cerebrovascular disease. In this context, several risk scores for cardiovascular disease are described, including the Framingham risk score, undoubtedly the most used. The final score estimates the risk of fatal or nonfatal coronary events in 10 years, and also stratifies patients into risk categories: low ( $<10 \%$ events in 10 years), moderate $(10-20 \%)$, and high $(>20 \%)$. This index estimates a prognosis and suggests the necessary clinical interventions. In the present study, the Framingham risk score was used to evaluate 159 patients, as it should only be used in patients $30-74$ years old without coronary artery disease. Of those, $47.2 \%$ had moderate risk and $8.8 \%$ had high risk for the development of coronary heart diseases in 10 years. Forty-five patients $(28.3 \%)$ had a Framingham risk score higher 
than expected for an individual of the same sex and age. The mean Framingham score was $10.5 \pm 9.1$, which is considered high, especially when compared with other studies involving the Brazilian population. Rodrigues et al., based on a cross-sectional study with 329 patients aged 31-70 years, found a mean Framingham risk score of $5.7 \% \cdot{ }^{37}$ Additionally, Landim et al., based on a sample of 107 drivers aged 30-74 years, found a mean score of $5 \% \cdot{ }^{38}$ In our study, there was a statistically significant difference when we compared females and males, which can be explained by the fact that the Framingham score has a lower discriminative power among women. With regard to studies on patients with psoriasis, our data are similar to the case-control study conducted by Gisondi et al. Based on a study with 234 psoriasis patients and 234 controls, a higher mean score was found in patients when compared with controls (11.2 vs. 7.3), $\mathrm{p}<0.001 .^{39}$ Likewise, there was no correlation of psoriasis severity and duration with the score. Fernandez et al., in a recent study of 395 patients, also found similar results: $30.5 \%$ of patients with moderate risk score and $11.4 \%$ with high risk scores (77). Similarly to our study, there was no relationship between the scores and the severity of the skin condition. ${ }^{40}$

\section{CONCLUSIONS}

We found an increased prevalence of $\mathrm{SH}$, type 2 diabetes, MS, and obesity in patients compared with the general population. Increased waist circumference was also found in addition to a considerable prevalence of depression and regular intake of alcohol. An association with smoking was described, with a mean pack-years being considered high tobacco intake.

Patients' cardiovascular risk profile was high according to the Framingham risk score, and $47.2 \%$ of patients had moderate or high risk of fatal and non-fatal coronary events in 10 years. The mean Framingham score was considered high when compared with other studies involving the Brazilian population.

It is noteworthy that psoriasis may manifest as a multisystem disease not restricted to the skin and its appendages. The association of psoriasis with several comorbidities may occur due to various factors, such as the chronic inflammatory nature of the disease, genetic susceptibility, environmental factors and/or related to the patient's quality of life and even adverse effects of drugs used for systemic therapy. Comorbidities that are associated with psoriasis greatly increase the morbidity and mortality of the disease. Therefore, it should be noted that the approach of the psoriatic patient should be comprehensive and multidisciplinary to implement preventive and early therapeutic measures aiming to improve the rates of mortality, hospitalization, and survival. 


\section{REFERENCES}

1. Christophers E. Psoriasis-epidemiology and clinical spectrum. Clin Exp Dermatol. 2001;26:314-20

2. Christophers E. Comorbidities in psoriasis. Clin Dermatol. 2007;25:529-34.

3. Gottlieb AB, Dann F. Comorbidities in patients with psoriasis. Am J Med 2009;122:1150.e1-9.

4. Kimball $A B$, Wu Y. Cardiovascular disease and classic cardiovascular risk factors in patients with psoriasis. Int J Dermatol. 2009;48:1147-56.

5. Prey S, Paul C, Bronsard V, Puzenat E, Gourraud PA, Aractingi S, et al. Cardiovascular risk factors in patients with plaque psoriasis: a systematic review of epidemiological studies. J Eur Acad Dermatol Venereol. 2010;24:23-30.

6. Gelfand JM, Neimann AL, Shin DB, Wang X, Margolis DJ, Troxel AB. Risk of myocardial infarction in patients with psoriasis. JAMA. 2006;296:1735-41.

7. Ludwig RJ1, Herzog C, Rostock A, Ochsendorf FR, Zollner TM, Thaci D, et al. Psoriasis: a possible risk factor for development of coronary artery calcification. Br J Dermatol. 2007;156:271-6.

8. Späh F. Inflammation in atherosclerosis and psoriasis: common pathogenic mechanisms and the potential for an integrated treatment approach. $\mathrm{Br} \mathrm{J}$ Dermatol. 2008;159:10-7.

9. Martins GA, Arruda L, Mugnaini ASB. Validation of life quality questionnaires for psoriasis patients. An Bras Dermatol. 2004;79:521-35.

10. Fortes C, Mastroeni S, Leffondré K, Sampogna F, Melchi F, Mazzotti E, et al. Relationship between smoking and the clinical severity of psoriasis. Arch Dermatol. 2005;141:1580-4.

11. Sommer DM, Jenisch S, Suchan M, Christophers E, Weichenthal M. Increased prevalence of the metabolic syndrome in patients with moderate to severe psoriasis. Arch Dermatol Res. 2006;298:321-8.

12. Fredriksson T, Pettersson U. Severe psoriasis--oral therapy with a new retinoid. Dermatologica. 1978;157:238-44.

13. Finlay AY. Current severe psoriasis and the rule of tens. Br J Dermatol. 2005;152:861-7.

14. Mehta NN, Azfar RS, Shin DB, Neimann AL, Troxel AB, Gelfand JM. Patients with severe psoriasis are at increased risk of cardiovascular mortality: cohort study using the General Practice Research Database. Eur Heart J. 2010;31:1000-6.

15. Neimann AL, Shin DB, Wang X, Margolis DJ, Troxel AB, Gelfand JM. Prevalence of cardiovascular risk factors in patients with psoriasis. J Am Acad Dermatol. 2006;55:829-35.

16. Spósito A, Carmelli B, Fonseca FA, Bertolami MC, Afiune Neto A, Souza AD, et al. IV Diretriz brasileira sobre dislipidemias e prevenção da aterosclerose: Departamento de Aterosclerose da Sociedade Brasileira de Cardiologia. Arq Bras Cardiol. 2007:88:3-19.

17. Executive Summary of The Third Report of The National Cholesterol Education Program (NCEP) Expert Panel onDetection, Evaluation, And Treatment of High Blood Cholesterol In Adults (Adult Treatment Panel III). JAMA. 2001;285:2486-97.

18. Wilson PW, D'Agostino RB, Levy D, Belanger AM, Silbershatz H, Kannel WB. Prediction of coronary heart disease using risk factor categories. Circulation. 1998;97:1837-47.

19. Salaroli LB, Barbosa GC, Mill JG, Molina MC. Prevalence of metabolic syndrome in popuIation-based study, Vitória, ES-Brazil. Arq Bras Endocrinol Metabol. 2007;51:1143-52.

20. Kleinert S, Feuchtenberger M, Kneitz C, Tony HP. Psoriatic arthritis: clinical spectrum and diagnostic procedures. Clin Dermatol. 2007;25:519-23.

21. Moll JM, Wright V. Psoriatic arthritis. Semin Arthritis Rheum. 1973;3:55-78.

22. Bonfiglioli R, Conde RA, Sampaio-Barros PD, Louzada-Junior P, Donadi EA, Bertolo MB. Frequency of HLA-B27 alleles in Brazilian patients with psoriatic arthritis. Clin Rheumatol. 2008;27:709-12.

23. Gottlieb A, Korman NJ, Gordon KB, Feldman SR, Lebwohl M, Koo JY, et al. Guidelines of care for the management of psoriasis and psoriatic arthritis: Section 2. Psoriatic arthritis: overview and guidelines of care for treatment with an emphasis on the biologics. J Am Acad Dermatol. 2008;58:851-64.

24. Tan ES, Chong WS, Tey HL. Nail Psoriasis: A Review. Am J Clin Dermatol. 2012;13:375-88.

25. Lean ME, Han TS, Morrison CE. Waist circumference as a measure for indicating need for weight management. BMJ. 1995;311:158-61.

26. Brasil. Ministério da Saúde. Secretaria de Vigilância em Saúde. Vigitel Brasil 2011: Vigilância de Fatores de Risco e Proteção para Doenças Crônicas por Inquérito Telefônico. Brasília: Ministério da Saúde, 2012. 132 p. (Série G. Estatística e Informação em Saúde).

27. Kimball AB, Robinson D Jr, Wu Y, Guzzo C, Yeilding N, Paramore C, et al. Cardiovascular disease and risk factors among psoriasis patients in two US healthcare databases, 2001-2002. Dermatology. 2008;217:27-37.

28. Azfar RS, Seminara NM, Shin DB, Troxel AB, Margolis DJ, Gelfand JM. Increased risk of diabetes mellitus and likelihood of receiving diabetes mellitus treatment in patients with psoriasis. Arch Dermatol. 2012;148:995-1000.

29. Gottlieb $A B$, Dann F, Menter A. Psoriasis and the metabolic syndrome. J Drugs Dermatol. 2008;7:563-72.
30. Langan SM, Seminara NM, Shin DB, Troxel AB, Kimmel SE, Mehta NN, et al. Prevalence of metabolic syndrome in patients with psoriasis: a population-based study in the United Kingdom. J Invest Dermatol. 2012;132:556-62.

31. Armstrong AW, Armstrong EJ, Fuller EN, Sockolov ME, Voyles SV. Smoking and pathogenesis of psoriasis: a review of oxidative, inflammatory and genetic mechanisms. $\mathrm{Br}$ J Dermatol. 2011;165:1162-8.

32. Reichert J, Araújo AJ, Gonçalves CM, Godoy I, Chatkin JM, Sales MP, et al. Smoking cessation guidelines - 2008. J Bras Pneumol. 2008;34:845-80.

33. Cassano N, Vestita M, Apruzzi D, Vena GA. Alcohol, psoriasis, liver disease, and antipsoriasis drugs. Int J Dermatol. 2011;50:1323-31.

34. Poikolainen K, Reunala T, Karvonen J, Lauharanta J, Kärkkäinen P. Alcohol intake: a risk factor for psoriasis in young and middle aged men? BMJ. 1990;300:780-3.

35. Qureshi AA, Dominguez PL, Choi HK, Han J, Curhan G. Alcohol intake and risk of incident psoriasis in US women: a prospective study. Arch Dermatol. 2010;146:1364-9.

36. Schmitt J, Ford DE. Psoriasis is independently associated with psychiatric morbidity and adverse cardiovascular risk factors, but not with cardiovascular events in a population-based sample. J Eur Acad Dermatol Venereol. 2010;24:885-92.

37. Rodrigues TF, Philippi ST. Nutritional evaluation and cardiovascular risk in executives submitted to a check-up. Rev Assoc Med Bras. 2008;54:322-7.

38. Landim MB, Victor EG. Framingham score for public transportation drivers in the city of Teresina, Piauí. Arq Bras Cardiol. 2006;87:315-20.

39. Gisondi P, Farina S, Giordano MV, Girolomoni G. Usefulness of the Framingham risk score in patients with chronic psoriasis. Am J Cardiol. 2010;106:1754-7.

40. Fernández-Torres R, Pita-Fernández S, Fonseca E. Fonseca E. Psoriasis and cardiovascular risk. Assessment by different cardiovascular risk scores. J Eur Acad Dermatol Venereol. 2013;27:1566-70.

How to cite this article: Baeta IGR, Bittencourt FV, Gontijo B, Goulart EMA. Comorbidities and cardiovascular risk factors in patients with psoriasis. An Bras Dermatol. 2014;89(5):735-44. 